\title{
PROJETOS DE SOCIEDADE E DE EDUCAÇÃO NA AMÉRICA LATINA DE HOJE : CONSTRUINDO CATEGORIAS DE ANÁLISE
}

\section{Adriana A. Sales de Melo}

\section{RESUMO}

Buscando elementos para construir a categoria de Projetos de Sociedade e de Educação, para a análise do planejamento e políticas educacionais na América Latina de hoje, este texto procura criticar exemplos de paradigmas de racionalidade que pretendem explicar estes movimentos do real, ora numa direção crítica, ora reificadora e técnica-instrumental.

\section{PALAVRAS-CHAVE}

Educação - América Latina; Sociedade - América Latina

\section{ABSTRACT}

Searching elements to buid a research category - Society and Education Projects - to a planning and educational policy analysis about the Latin America today, this article demands to criticize racionality paradigms examples, that intend to explain those real moviments, in a critical direction and also in a technical-instrumental and reified direction.

\section{KEYWORDS}

Education - Latin America; Society - Latin America 


\section{INTRODUÇÃO}

Este artigo é resultado das leituras e discussões realizadas no início de 1999, na disciplina 'Política Educacional na América Latina', orientada pelo Prof.Dr. Nilson Joseph Demange, seguindo a sugestão de discussão de aspectos que relacionem elementos de nosso projeto de pesquisa aos paradigmas mais atuais de construção de nossa realidade social e educacional.

No nosso trabalho de pesquisa, queremos saber como se realiza o processo de socialização do saber proporcionado pelo nosso sistema educativo, analisando a sua direção ora no sentido da ótica do capital, ora no sentido da ótica do trabalho; a partir dos projetos atuais de sociedade e de educação dos sujeitos políticos coletivos que interferem nos rumos das políticas educacionais na América Latina, acompanhando o movimento de suas realizações nos anos 90 e início do próximo século.

Assim, um dos elementos conceituais principais que deve ser construído, a partir da materialização e explicitação histórica de nossas políticas educacionais atuais, é a noção de "projetos de sociedade e de educação"; considerando que o Estado é a condensação de uma correlação de forças sociais que revelam (nos seus embates históricos, no âmbito do industrialismo e da democracia) suas intenções sobre a sociedade (e a educação), que cada sujeito político coletivo deseja tornar hegemônica para todos os demais.

Aprofundar e esclarecer o conceito de Projeto de Sociedade e de Educação, tentando tornar visível sua importância fundamental para as discussões político-educacionais, significa também discutir sobre o pluralismo que deveria fundamentar a nossa vivência democrática. Significa também resgatar a importância do sujeito e da subjetividade na luta de classes; considerando as profundas contradições que nossa diversidade cultural impõe ao ritmo e direção das mudanças pelas quais passa nosso modo social de produção hoje.

Afirmar que existem projetos de sociedade e de educação em conflito, mostrando as tendências hegemônicas de sua materialização, demanda também uma discussão sobre a questão de poder na nossa correlação atual de forças sociais. 
Significa tentar identificar e esclarecer quais sujeitos políticos coletivos participam das instâncias de decisão e de planejamento educacionais dos nossos países e como suas propostas interagem para a materialização de um projeto hegemônico de sociedade e de educação. Hegemônico, mas plural; consensual, mas pleno de contradições; às vezes exposto à sociedade com clareza, às vezes implícito em atos políticos, às vezes oculto nas entrelinhas de documentos e ações oficiais.

A base teórica de investigação sócio-histórica destes Projetos, certamente vai interferir no resultado das análises. Não existe ciência sem ideologia, e nossa posição política aponta para a possibilidade da construção de tendências de confronto à hegemonia neoliberal que se consolidou nos países latino-americanos nos anos 90. Aponta para a possibilidade de construção de um projeto democrático de massas (para a sociedade e para a educação), o que exige a definição da educação que queremos para todos.

A viabilidade da construção teórica desta categoria (Projetos de Sociedade e de Educação) se encontra na materialização do planejamento educacional como explicitação de que objetivos e metas cada sujeito político coletivo significativo constrói no âmbito políticoeducacional. É uma categoria que envolve a dimensão histórica atual destes sujeitos em sua atuação política, ora no âmbito da sociedade civil, ora como agentes da burocracia estatal, ora entre os intermeios desta burocracia estatal pública com a esfera de interesses sociais privados. As intenções explícitas destes sujeitos políticos coletivos em relação à direção das políticas educacionais; sua vontade nem sempre traduzida em objetivos e estratégias políticas de ação (para a realização de seu Projeto de Sociedade e de Educação); o interesse ou entendimento que cada sujeito constrói nas suas ações; revelam tanto uma direção que querem tornar hegemônica quanto uma heterogeneidade de projetos e ações, quanto esclarecimentos de diferentes níveis de objetividade.

São formas diferentes de construção social-racional da realidade que se constituem como projetos de sociedade e de educação. 


\section{MOMENTO EXPLICATIVO}

Um dos instrumentos que podem dar suporte teórico à investigação da realização/materialização histórica destes Projetos, enquanto planejamento educacional, pode estar em algumas das indicações básicas de Matus (1993), que indica elementos para que cada planejamento seja eficiente para o alcance de seus objetivos: como a necessidade de mediações entre o futuro e o presente, o passado e o futuro; a necessidade de uma ação (central) a buscar coerência global ante as ações parciais dos diversos atores e, principalmente, a necessidade de uma mediação entre o conhecimento e a ação.

O planejamento estratégico se constrói a partir de um tipo de ação humana: "(...) a ação intencional e reflexiva, mediante a qual o produtor da ação espera conscientemente lograr determinados resultados numa situação de cooperação ou conflito com os outros." (MATUS, 1993:81) Em relação aos aspectos históricos atuais de nosso planejamento educacional, estas ações têm origem tanto mais intencional e reflexiva quanto mais conservadores (no sentido de avessos às mudanças sociais para resolver os problemas sociais que eles mesmos diagnosticam) são os sujeitos políticos coletivos; no entanto, é a partir desta "ação intencional e reflexiva", que pretendemos construir uma das bases epistemológicas fundamentais para a categoria de Projeto de Sociedade e de Educação.

Dentro da forma instrumental do Planejamento Estratégico Situacional, consideramos o momento explicativo como início fundamental de nosso projeto de pesquisa, de análise da totalidade social da qual nosso objeto participa; no sentido em que tentamos, de uma forma auto-reflexiva, investigar as condições históricas de realização do planejamento educacional de diversos sujeitos políticos coletivos.

Para isto, procuramos analisar: a) a relação destes atores com a totalidade social complexa na qual interagem; b) o valor atual que as questões educacionais apresentam para estes atores em suas mediações com o passado e o futuro, bem como tentar delinear historicamente suas ações políticas educacionais; c) a "eficiência" com que estes atores enfrentam a materialização de seu planejamento educacional, no sentido de realizar seus projetos de sociedade e de educação; bem como d), mediando a investigação entre conhecimento e ação, analisar a "oportunidade e a possibilidade" (MATUS, 1993:304) que estes atores tiveram, nos anos 90, de realizar seus Projetos de Sociedade e de Educação. 


\title{
3. CRITICANDO UM EXEMPLO DE PARADIGMA DE RACIONALIDADE TÉCNICA-INSTRUMENTAL
}

\begin{abstract}
Nos termos de Habermas, a ação e a linguagem instrumentais, orientadas para a realização técnica, deslocaram aqui a ação e a linguagem comunicativas, interessadas na reciprocidade e na autocompreensão sem intenções manipulatórias. As questões públicas são apresentadas como problemas tecnicamente solúveis, inapropriados à discussão pública, enquanto a ideologia tenta substituir as considerações morais por construções científicas que justifiquem um regime tecnocrático de administração da crise, impedir a compreensão da estrutura social e, ao contrário das ideologias anteriores, desencorajar a espera de uma "boa vida" prometida ou alcançável. (MORSE, 1988, p.151)
\end{abstract}

Tentando discutir as bases de uma investigação crítica, que esclareça, assuma e realize especificamente aspectos contraditórios do conflito social em que se constrói o planejamento educacional enquanto confronto entre Projetos de Sociedade e de Educação de diversos Sujeitos Políticos Coletivos, procuramos inicialmente localizar historicamente alguns aspectos da política educacional na Argentina entre os anos 80 e 90 a partir de fontes secundárias, de textos escritos sobre o movimento histórico atual, que citam documentos e ações que nortearam este processo.

A seguir apresentaremos algumas informações/interpretações presentes em dois textos que consideramos básicos para esta discussão, pela sua atualidade e abrangência apesar de um ser um artigo e outro uma tese de doutoramento:

1 - Primeiramente trataremos de apontamentos de leitura de um artigo de Cecília Braslavsky (1998), onde a autora procura mostrar como se construíram as características histórico-educacionais principais da transição para o modelo societal democrático (modelo para armar), na Argentina dos anos 80, como oposição clara ao modelo de "congelamento político".

Concebia-se nesta transição (a partir de 1983 - eleições em 1984) um estado democrático, produtivo, moderno, livre de condicionamentos externos e socialmente justo.

Até os anos 70, a Argentina, (como o Brasil) vive um processo de modernização conservadora, com índices de desenvolvimento social e econômico crescentes em relação aos outros países latino-americanos; no entanto, alguns fatos colocaram um limite, um teto a esta 
modernização, tornando mais lento o processo de desenvolvimento. São citados: "la cosolidación de mecanismos de planificación y gestión verticalizantes en todas las áreas de accion, poco propicios para promoción de la resolución de los problemas de los grupos menos favorecidos de la población." (77)

Algumas tendências e características da economia Argentina até 1993, bem como de desenvolvimento social, e do crescimento da marginalidade social, caracterizam este processo de transição. A autora analisa dados das três últimas décadas sobre três conjuntos principais de problemas, que causaram uma "marginalização" educativa.

"(...) 1) la total exclusión de las habilidad de leer y escribir; 2) la temprana marginación de los sistemas de educación formal, antes que esas habilidades básicas se hayan consolidado y 3) la permanencia en los sistemas de educación normal sin que se logre al acceso y el entrenamiento en la adquisición de esas mismas habilidades." (82)

Em relação ao ensino fundamental:

"(...) el retroceso de Argentina en su posición relativa en la escala de países latinoamericanos de acuerdo al lugar que ocupabam en el cumplimento del objetivo de escolarización primaria para todos los niños de 6 a 12 años de edad. En 1950 ocupaba el segundo lugar, en 1960 el tercero, en 1970 el quinto lugar y en 1980, el noveno"(85), o que não quer dizer que não tenha havido avanços parciais.

São investigados neste texto diversos elementos que compõem a situação de marginalização educativa, como: a) o deficiente rendimento quantitativo do sistema de educação (como taxas crescentes de evasão e repetência); b) a permanência no sistema educativo sem logros de aprendizagem, com uma especial atenção para o nível de alcance dos objetivos curriculares: em muitas escolas públicas, o modelo segue sendo, hoje, o do "currículo da dependência", herdado do período entre 1976-1982.

Estas ações terminam por limitar o acesso ao saber, pelas classes populares, sendo marginalizantes.

Em 1983, o governo eleito convoca um segundo Congresso Pedagógico Nacional (o primeiro foi realizado em 1882), que coloca em confronto a capacidade de gestão das províncias e o projeto educacional (ou a falta dele) de diversos atores sociais, construindo a possibilidade de formular explicitamente o "modelo educativo para armar" (ou por armar). 
Uma das medidas implantadas mais rapidamente - 1984 - foi o ingresso direto às universidades.

A autora põe em relevo a atenção recente dada às questões da: a) educação continuada de jovens e adultos, bem como a sua capacitação profissional; b) a ampliação da rede inicial (ensino pré-escolar); c) o Programa Social Nutricional; d) os programas de atenção à população rural escolarizada.

Já a partir de 1982, começa-se a discutir e a implantar desenhos (grades) curriculares orientados à "participação ao saber elaborado" em oposição à "marginalização educativa" vivenciada pelo período de "congelamento político". Na municipalidade de Buenos Aires, este processo de renovação curricular ocorre com uma direção participativa (convocando-se pais para opinar e docentes para atuar) e uma investigação profunda do diagnóstico do currículo vigente (1984).

Em 1986, o Anteproyecto de Diseño Curricular para la Educación Primaria Común traz como consequências:

"(...) 1) la definición de que la escuela es una institución que comparte funciones con otras instituciones, pero que mientras que para el logro de algunas funciones las complementa (por ejemplo, a la familia para la socialización), para el logro de otras tiene un rol prioritario y específico; 2) la selección de contenidos de acuerdo a múltiples criterios; 3) el planteo de un desafío enriquecedor para las instituciones y los docentes frente a la necesidad de contenidos educativos y 4) la propuesta de articulación entre el saber elaborado y el saber que los chicos traen a la escuela." (111)

Enfim, este processo de transição do 'modelo para armar' apresentaria, relacionando formas velhas e novas, a recriação de um novo equilíbrio em matéria de equidade distributiva frente ao bem social educação, em cuja conformação a ação de todos os envolvidos em matéria educativa tem particular importância.

Para nossa pesquisa atual, este texto de Braslavsky tem uma importância especial na construção de nossa categoria de Projetos de Sociedade e de Educação, porque a autora nos mostra a história política educacional nos anos 80 na Argentina, como um processo em construção entre diversas forças sociais que interagem e se confrontam. Em outro texto (1989), a mesma autora define alguns dos atores principais que atuaram neste processo; associando os problemas educacionais atuais aos movimentos de construção hegemônica dos Projetos de Sociedade e de Educação destes atores; como partidos, forças armadas, igreja e o 
próprio Ministério de Educação e Cultura; bem como nos traz elementos para a discussão das constituições das províncias argentinas nos anos 80. Estes textos apresentam elementos para configurar a complexa rede de interesses e discursos que se constroem nesta época na Argentina.

Estes artigos citados são exemplos de uma forma de investigar a realidade a partir de um paradigma epistemológico que não reduz esta realidade a fatos, dados, ou à perspectiva de um único ator social; procurando construir um entendimento das políticas educacionais atuais na Argentina que reflete a interação entre os diversos sujeitos políticos coletivos em conflito real pela realização de seus Projetos de Sociedade e de Educação.

2 - Por outro lado, gostaríamos também de fazer uma crítica do texto de GENTILINI (1999), como um exemplo bem diferente de paradigma de interpretação do todo social, que se constrói na direção de uma razão (de uma ciência) utilizada como instrumento de apresentação técnica-instrumental de informações.

Nesta tese, apesar de ser proposta a análise dos atores múltiplos que participaram da transição democrática nos anos 80 e 90 em alguns países latino-americanos, estes atores não são definidos, reduzindo a complexidade da relação entre Estado e Mercado à relação entre as ações da burocracia estatal (identificada com o Estado) e de sujeitos privados (identificados com o Mercado).

Sem considerar a diversidade e multiplicidade de interesses divergentes neste processo histórico, bem como suas estratégias contraditórias, o autor mostra o ponto de vista unilateral de um dos atores principais do processo - UNESCO - como se fosse a expressão privilegiada de informações sobre este processo.

Apesar de necessitar de mais espaços de discussão sobre este texto, creio que as características principais de sua construção teórica refletem um modelo epistemológico que pode ser relacionado com o paradigma da racionalidade instrumental: um estudo que termina por reificar seu objeto de estudo, atendo-se à descrição de fatos históricos, de um ponto de vista unilateral, apresentando sujeitos que parecem não agir em conflito, não interagindo na construção social daquele movimento histórico político-educacional. Ao nosso ver, este texto procura, de forma paradoxal, construir uma história sem historicidade, proclamando a existência de fatos que se desenvolvem como que progressivamente, sem rupturas nem embates e correlações de forças sociais; onde a existência de atores sociais é proclamada 
como fundamento do processo de 'crise e planejamento educacional', mas não é considerada como objeto de análise.

A concepção de planejamento, também, acaba por revelar um conceito factual de sua realização, um planejamento que não entra em contradição, como se descrevendo ações que se desenrolam numa atualidade perene. Desta forma, cremos que o planejamento educacional se torna inútil, já que não se relaciona com movimentos passados, nem procura mediações com o futuro (MATUS, 1991).

\begin{abstract}
"O aspecto não controvertido das coisas, a fachada inerte dos dados classificados, passa a ser objetivo, enquanto que qualquer coisa que rompa essa fachada, reclame experiência específica, descarte as idéias recebidas e infrinja o plácido consenso é rechaçada como subjetiva. Isso quer dizer que a objetividade não faz senão refletir os calculados acordos dos comitês, comissões, fundos e fundações que engendram e administram as indústrias da cultura e da educação. O planejamento perde autonomia e a confiança para abarcar a realidade, e o discurso transforma-se em pura comunicação, em vez de uma auto-expressão que poderia provocar dúvidas e desagradar a audiência." (MORSE, 1988:153)
\end{abstract}

Enfim, os comentários que construímos neste artigo não pretendem ser mais do que aproximações a algumas das características que consideramos de fundamental importância para entender alguns dos paradigmas mais atuais de construção de nossa realidade social, sempre com a preocupação teórica da construção de categorias de análise que nos possibilitem a compreensão, esclarecimento e construção de nossas políticas-educacionais atuais, como o conceito de Projetos de Sociedade e de Educação.

A construção de qualquer trabalho conceitual - como a interpretação das contradições da racionalidade técnico-instrumental com a qual realizamos, hoje, nosso modo social de produção - exige a crítica e superação dialética das categorias que já conhecemos, a partir da observação e análise de nossa realidade social, procurando sempre relacionar formas passadas e atuais de existência desta realidade. 


\section{REFERÊNCIAS}

BRASLAVSKY, Cecilia. Perspectivas de la educación y de la alfabetización en Argentina en el marco de la democracia. In:

Latina y el Caribe. Brasília : INEP, 1988. p. 75-118

BRASLAVSKY, Cecilia et al. Educación en la transición a la democracia : casos de Argentina, Brasil y Uruguay. Santiago : UNESCO/OREALC, 1989.

GENTILINI, João Augusto. Crise e planejamento educacional América Latina : tendências e perspectivas do contexto de descentralização. Campinas, SP, 1999. Tese (Doutorado). Faculdade de Educação, UNICAMP.

MATUS, Carlos. Política, Planejamento e Governo. Brasília, DF : IPEA, 1993.

MELO, Adriana A. Sales. Educação e hegemonia no Brasil de hoje. Maceió : EDUFAL, 1998.

MORSE, Richard M. O espelho de próspero : cultura e idéias nas Américas. Trad. Paulo Neves. São Paulo: Cia. Letras, 1988. 